\title{
MICROMACHINED PMN-PT SINGLE CRYSTAL FOR ADVANCED TRANSDUCERS
}

\author{
Xiaoning Jiang ${ }^{1}$, Jian R. Yuan ${ }^{2}$, An Cheng ${ }^{3}$, Guy Lavallee ${ }^{3}$, Paul Rehrig ${ }^{1}$, Kevin Snook ${ }^{1}$, Seongtae Kwon ${ }^{1}$, \\ Wesley Hackenberger ${ }^{1}$, Jeffrey Catchmark ${ }^{3}$, John McIntosh ${ }^{3}$ and Xuecang Geng ${ }^{4}$ \\ ${ }^{1}$ TRS Technologies, Inc., 2820 East College Ave., State College, PA 16801. \\ ${ }^{2}$ Boston Scientific Corporation, IVUS Technology Center, 47900 Bayside Parkway, Fremont, \\ CA 94538 \\ ${ }^{3}$ Nanofabrication Facility, The Pennsylvania State University, 188 Materials Research Institute, University Park, \\ PA 16802-7003 \\ ${ }^{4}$ Blatek, Inc., 2820 East College Avenue, Suite F., State College, PA 16801
}

\begin{abstract}
In this paper a deep reactive ion etching (DRIE) process developed for the micromachining of bulk piezoelectrics is discussed. For the first time, a PMN-PT single crystal piezoelectric micro-array was fabricated with an array post cross section size of $14 \mu \mathrm{m} \times 14 \mu \mathrm{m}$, a height of $>60 \mu \mathrm{m}$, and a spacing between microposts of about 2-6 $\mu \mathrm{m}$. The etched single crystal piezoelectrics retained high piezoelectricity $\left(\mathrm{d}_{33} \sim 2000 \mathrm{pC} / \mathrm{N}\right)$ and low dielectric loss $(<0.01)$. Single crystal/epoxy 1-3 composites were fabricated using the etched micro-arrays and the electromechanical coupling coefficient of such piezoelectric composites was $\sim 0.72$, indicating promising applications such as micro-sensors, actuators and transducers.
\end{abstract}

\section{INTRODUCTION}

Thin film, thick film and bulk piezoelectric materials have been widely used for a broad range of sensors, actuators and transducers. Thin and thick piezoelectric films such as $\mathrm{ZnO}$, AlN and PZT have been more popular for piezoelectric microdevices or piezo-MEMS because of the ability to use microfabrication processes. However, the piezoelectric properties of films are significantly lower compared with their bulk counterparts, for example, electromechanical coefficients of thin and thick films of PZT are inferior to those of bulk PZT by a factor of 2-5 [1], which means that the performance of piezo MEMS devices could be further improved by using piezoelectrics with advanced properties. Various film and bulk piezoelectric materials properties are compared in Table 1. Single crystal piezoelectrics based on $\mathrm{Pb}\left(\mathrm{Zn}_{1 / 3} \mathrm{Nb}_{2 / 3}\right)_{1-\mathrm{x}} \mathrm{Ti}_{\mathrm{x}} \mathrm{O}_{3}(\mathrm{PZN}-\mathrm{PT})$ or $\mathrm{Pb}\left(\mathrm{Mg}_{1 / 3} \mathrm{Nb}_{2 / 3}\right)_{1-\mathrm{x}} \mathrm{Ti}_{\mathrm{x}} \mathrm{O}_{3}(\mathrm{PMN}-$ $\mathrm{PT})$ exhibit large increases in strain over conventional piezoelectric ceramics (Figure 1) due to the ability to orient the crystals along a preferred high strain crystallographic direction [2]. The crystals' piezoelectric strain remains nearly hysteresis free up to levels of $\sim 0.5$ to $0.6 \%$ depending on the crystal composition, which is desired for many piezoelectric actuation. Also because of the considerably higher piezoelectric coefficients and electromechanical coupling factors, single crystals are being used to fabricate ultrasound transducers $(<20 \mathrm{MHz})$ with unprecedented bandwidth $(>100 \%)$ and sensitivity [3-6].

Both dry etching (plasma and RIE etching) and wet etching methods can be used to pattern piezoelectric thin films for piezoMEMS, but precise patterning or micromachining of bulk piezoelectrics and thick PZT films has been very difficult and that's why most of the research and development efforts were directed to thin film based micro-sensor, actuator and transducers. Anisotropic dry etching of PZT has drawn a lot of attention, and some interesting results have been achieved [7-10]. In addition to the advances in PZT dry etching, some major plasma and RIE etching tool suppliers such as Tegal and Oxford Instruments have specific tools and processes aimed at the PZT etching market. Table 2 presents etching chemistry, etch rate, and sidewall profile characteristics. Recent progress on deep PZT dry etching has shown $>100 \mu \mathrm{m}$ etch with an etching side wall angle of $\sim 76^{\circ}$ $[7,10]$, which may be good for most of the piezo-MEMS fabrication. The goal of this work was to further develop a dry deep etching process with a better etching profile for fabrication of a PMN-PT single crystal piezoelectric micro-array, which is necessary to fabricate advanced high frequency ultrasound transducers [11].

In this paper, a deep etching process for PMN-PT single crystal was investigated for micromachined piezoelectric sensor, actuator and transducer applications. The possible crystal degradation because of the etching damage was also investigated. Various single crystal /epoxy 1-3 composites were prepared and characterized for advanced high frequency transducers.

Table 1. Film and bulk piezoelectric materials properties.

\begin{tabular}{|c|c|c|c|}
\hline $\begin{array}{c}\text { Piezoelectric } \\
\text { materials }\end{array}$ & $\begin{array}{c}\text { Piezoelectric } \\
\text { coefficient } \\
(\mathrm{pC} / \mathrm{N})\end{array}$ & $\begin{array}{l}\text { Young's } \\
\text { Modulus } \\
(\mathrm{GPa})\end{array}$ & $\begin{array}{c}\text { Electro- } \\
\text { mechanical } \\
\text { coupling }\end{array}$ \\
\hline AlN (film) & $\mathrm{d}_{31} \sim-2$ & 330 & $\mathrm{k}_{\mathrm{t}} \sim 0.24$ \\
\hline $\mathrm{ZnO}$ (film) & $\mathrm{d}_{31} \sim-5$ & 210 & $\mathrm{k}_{\mathrm{t}} \sim 0.27$ \\
\hline $\begin{array}{l}\text { PZT (sol-gel, } \\
\text { sputtering) }\end{array}$ & $\mathrm{d}_{31} \sim-100$ & 40 & $\mathrm{k}_{33} \sim 0.39$ \\
\hline PZT (Bulk) & $\begin{array}{l}\mathrm{d}_{33}, \sim 600 \\
\mathrm{~d}_{31} \sim-300\end{array}$ & 70 & $\begin{array}{l}\mathrm{k}_{31} \sim 0.4 \\
\mathrm{k}_{33} \sim 0.7\end{array}$ \\
\hline $\begin{array}{l}\text { Single crystal } \\
\text { (bulk) }\end{array}$ & $\begin{aligned} & d_{33} \sim 2000 \\
& d_{31} \sim-1000 \\
&\end{aligned}$ & 12 & $\begin{array}{l}\mathrm{k}_{31} \sim 0.85, \\
\mathrm{k}_{33} \sim 0.93\end{array}$ \\
\hline
\end{tabular}

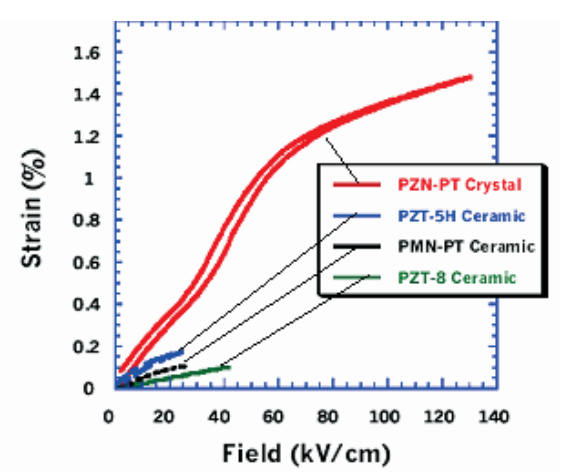

Figure 1. Piezoelectric strain response from single PZN-PT single crystal material compared to piezoelectric and electrostrictive ceramics. The crystal strain remains nearly hysteresis free up to $\sim 0.6 \%$. At high fields very large strains $>1 \%$ can be achieved but with an increase in hysteresis. 
Table 2. PZT dry etching .

\begin{tabular}{|l|l|l|l|}
\hline $\begin{array}{l}\text { Etch } \\
\text { Chemistry }\end{array}$ & Etch Rate & $\begin{array}{l}\text { Etch } \\
\text { Depth }\end{array}$ & $\begin{array}{l}\text { Side wall } \\
\text { Angle }\end{array}$ \\
\hline $\begin{array}{l}\mathrm{Cl}_{2} / \mathrm{Ar}, \\
\mathrm{C}_{2} \mathrm{~F}_{6} / \mathrm{Ar}, \\
\mathrm{Cl}_{2} / \mathrm{C}_{2} \mathrm{~F}_{6} / \mathrm{Ar}, \\
\mathrm{HBr} / \mathrm{Ar}\end{array}$ & $\begin{array}{l}900-1300 \\
\mathrm{~A} / \mathrm{min}\end{array}$ & $0.25 \mu \mathrm{m}$ & $50-80^{\circ}$ \\
\hline $\begin{array}{l}\mathrm{CF}_{4} / \mathrm{O}_{2}, \\
\mathrm{CF}_{4} / \mathrm{N}_{2}\end{array}$ & $\sim 60 \mathrm{~nm} / \mathrm{min}$ & - & \\
\hline $\mathrm{Cl}_{2} / \mathrm{CF}_{4}$ & $\sim 90 \mathrm{~nm} / \mathrm{min}$ & - & - \\
\hline $\mathrm{SF}_{6}$ & $300 \mathrm{~nm} / \mathrm{min}$ & $70 \mu \mathrm{m}$ & $\sim 75^{\circ}$ \\
\hline $\mathrm{SF}_{6}$ & $\sim 120$ & $2 \mu \mathrm{m}$ & $85-90^{\circ}$ \\
\hline $\mathrm{SF}_{6}, \mathrm{SF}_{6} / \mathrm{N}_{2}$, & $\sim 160$ & $>100 \mu \mathrm{m}$ & $\sim 72^{\circ}$ \\
$\mathrm{SF}_{6} / \mathrm{Ar}$ & $\mathrm{nm} / \mathrm{min}$ & & \\
\hline
\end{tabular}

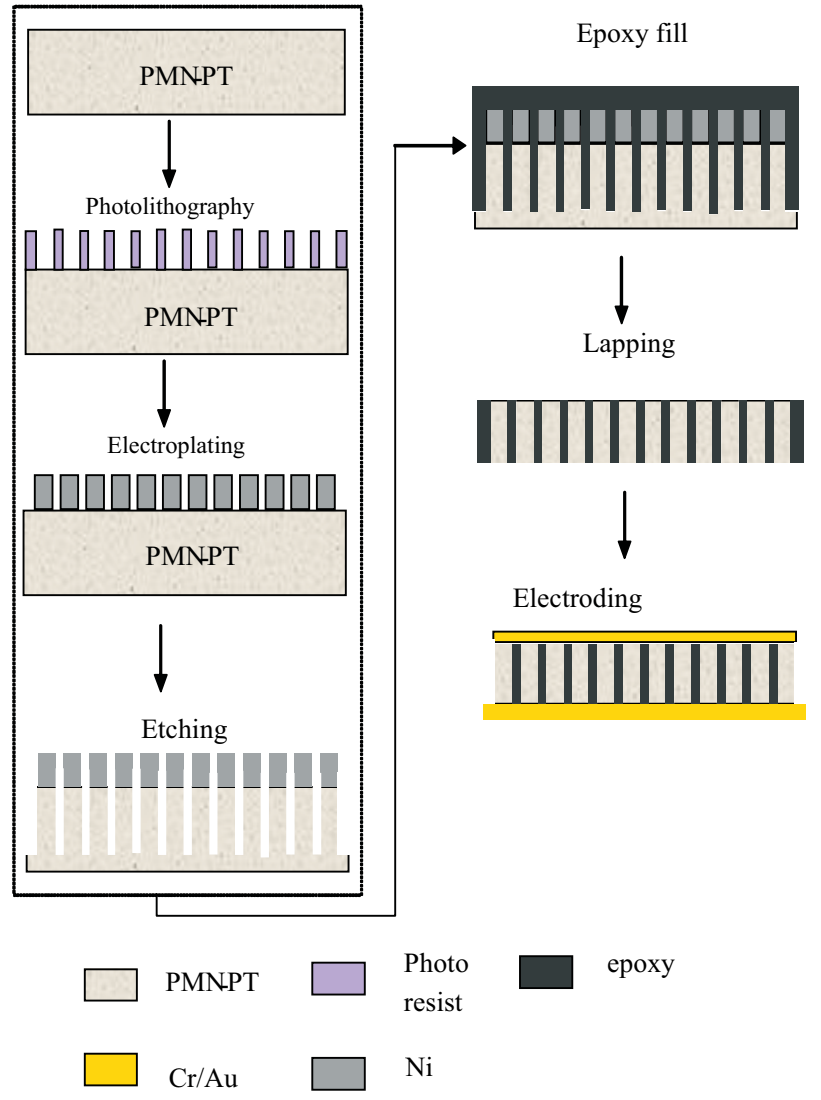

Figure 2. Schematic process flow for micromachined PMNPT/epoxy 1-3 composites.

\section{EXPERIMENTAL PROCEDURE AND RESULTS}

PMN-PT single crystal plates with $\mathrm{d}_{33}$ of $1800-2200 \mathrm{pC} / \mathrm{N}$, dielectric constant of 5000-7500, and dielectric loss $<0.01$ were prepared as wafers and lapped on both sides and polished on one side. For the wafer damage study, a wafer was etched without any additional wafer preparation. XRD characterization as well as d33 measurements were conducted on the damage-study wafer before and after etching. For PMN-PT micro-array fabrication, a wafer with a polished side was coated with $2000 \AA \mathrm{Ni}$ using an evaporator as an electroplating seed layer and then the wafer was ready for photoresist coating. A $15 \mu \mathrm{m}$ thick photoresist (SPR-220) was coated onto the wafer and baked at $110^{\circ} \mathrm{C}$ for 2 minutes. A direct laser writing lithography was used in this study to pattern the photoresist. A He-Cd laser with UV energy of $50 \mathrm{~mW}$ and wavelength of $442 \mathrm{~nm}$ was used. The exposed wafers were then developed and put into a $\mathrm{Ni}$ electroplating bath. After electroplating the wafers were soaked in acetone to strip the photoresist, and the wafer was then ready for etching. The PMNPT wafer with a Ni hard mask was then put into the etching chamber of the P5000 using a $\mathrm{Cl}_{2}$ based deep etching. The etched micro-array for high frequency 1-3 composites prototyping was then ready for epoxy filling, where the spacing between posts in micro-array was filled with epoxy to form the 1-3 composites. The epoxy was cured over night at room temperature. This was followed by a precise lapping process to remove the remnant crystal at the back and the epoxy at the front until the posts were exposed from both sides and the desired thickness was achieved. $\mathrm{Cr} / \mathrm{Au}$ electrodes were coated onto both sides of the composites and the composites were poled at $15 \mathrm{kV} / \mathrm{cm}$ at room temperature for a few minutes. Figure 2 shows the process flow for the micromachined high frequency 1-3 piezoelectric composite fabrication. The etching depth and the openings between posts were inspected using SEM. The impedance and phase spectrum and dielectric loss of the prototyped composites were recorded using a HP 4194A impedance analyzer, and the electromechanical coupling coefficients of the composites were then calculated using an IEEE standard [12].

The XRD pattern of the PMN-PT single crystal surface before and after $\mathrm{Cl} 2$ based deep etching is shown in Figure $3 \mathrm{a}$ and $3 \mathrm{~b}$, respectively. The prior and post etching patterns matched with each other closely, indicating no observable surface damage induced by the RIE processing. Figure $3 \mathrm{c}$ shows the strain vs. field property of the crystal after etching, which is also a typical strainfield curve for crystals without etching, meaning the piezoelectric properties were retained after etching. This experiment cleared the concern that the possible etching induced damage may affect the performance of micromachined single crystal piezoelectric devices. Laser lithography is the first step in fabrication of micromachined PMN-PT composites. Precision photoresist patterning helps define the Ni mask plated through the mold, and further affects the etching rate and depth. Figure 4 a shows Ni plating through a welldefined photoresist pattern, and Figure $4 \mathrm{~b}$ shows the Ni mask after stripping the plating and photoresist.

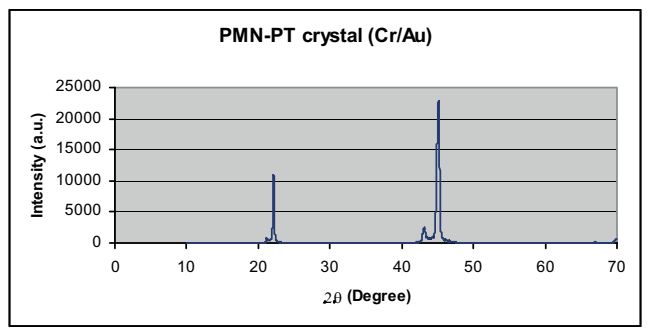

(a)

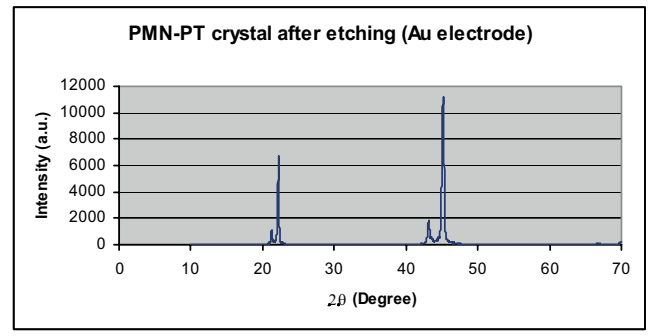

(b) 


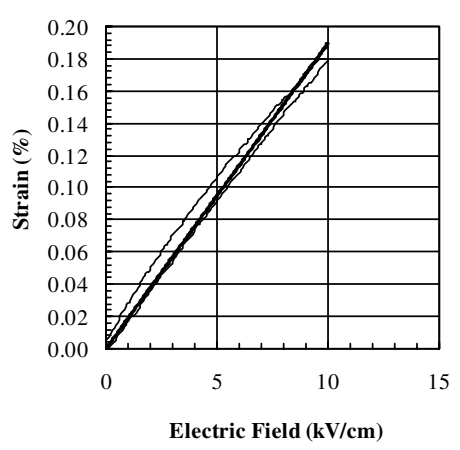

(c)

Figure 3. Experiments on the possible crystal property degradation induced by etching damage. (a) XRD pattern of crystal surface before etching. (b) XRD pattern of crystal surface after etching 9 hours . (c) Strain-field property of crystal after etching 9 hours.

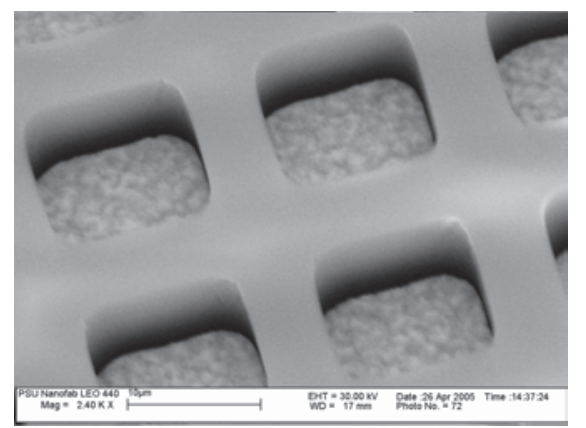

(a)

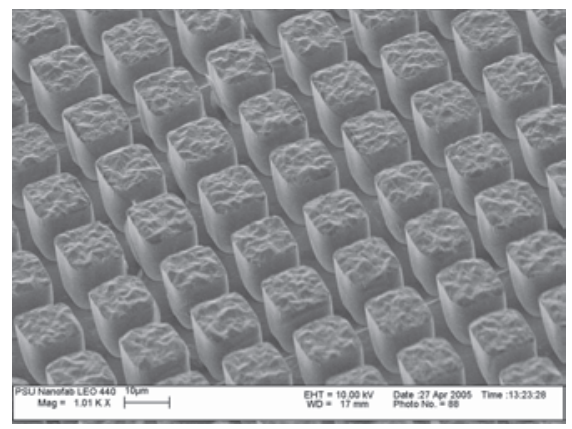

(b)

Figure 4. Photoresist and Ni pattern. (a) the photoresist pattern and plated Ni posts during plating. (b) the Ni post array after stripping the photoresist.

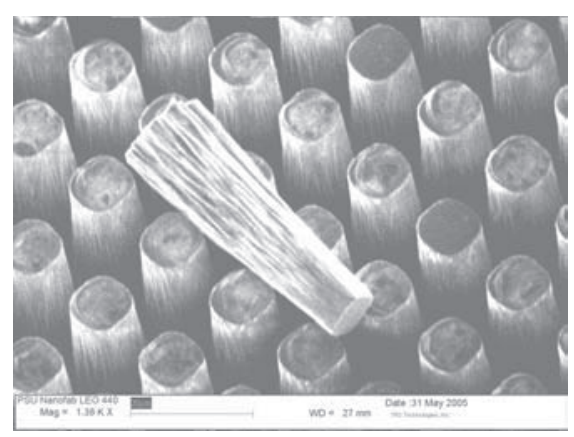

Figure 5. SEM picture of an etched PMN-PT single crystal micro-array.
The etching rate ratio of PMN-PT crystal to Ni is about more than 5 in this study. The obtained PMN-PT etching rate ranged from $2 \mu \mathrm{m} /$ hour to $8 \mu \mathrm{m} /$ hour depending on the pattern, exposed area, and etching conditions such as RF power, flowrate, etc [7-10]. Figure 5 shows a PMN-PT micro-array with posts of $\sim 67 \mu \mathrm{m}$ high, with a post height/width aspect ratio of $>4$. It is also noticed that the angle of etched side wall profile is $>87^{\circ}$, which allows precise and deep etching of more closely standing PMN-PT single crystal micro-arrays comparing to the PZT etching results published by other groups [7-10]. Figure 6 shows a photograph picture of the PMN-PT/epoxy 1-3 composite ready for characterization. The thickness of the prepared piezoelectric composites ranged from 20 $\mu \mathrm{m}$ to $60 \mu \mathrm{m}$. To characterize the piezoelectric micro-array, an impedance analyzer was used to record the impedance and phase vs. frequency (Figure 7) and the effective electromechanical coupling of the array was calculated to be $\sim 0.72$, which is close to its bulk material property and is very promising for advanced transducers with high sensitivity and broad bandwidth [13-15]. The composite with thickness of $31 \mu \mathrm{m}$ was used to fabricate a $40 \mathrm{MHz}$ ultrasound transducer, and the transducer characterization results showed significantly improved sensitivity and bandwidth compared with PZT transducers. The results of the $40 \mathrm{MHz}$ transducer characterization and animal imaging tests will be reported in another paper [16].

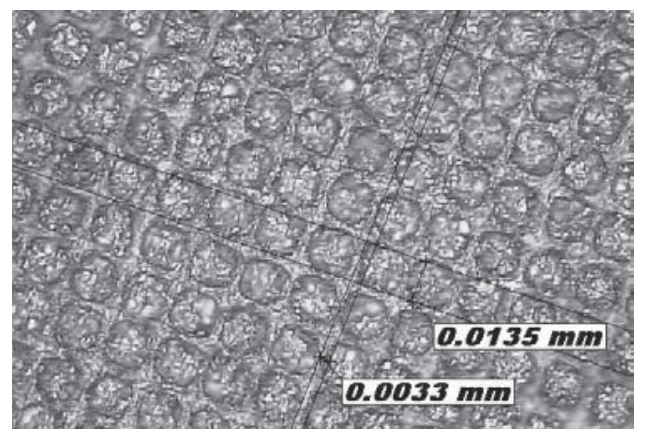

Figure 6. Photograph of a micromachined PMN-PT/epoxy 1-3 composite.

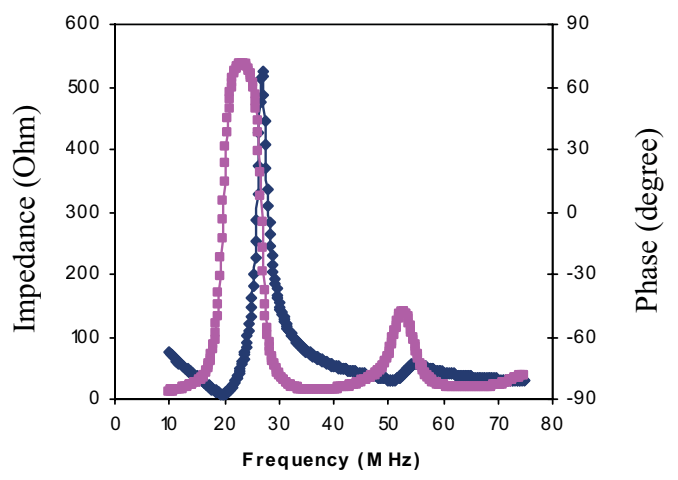

(a) 


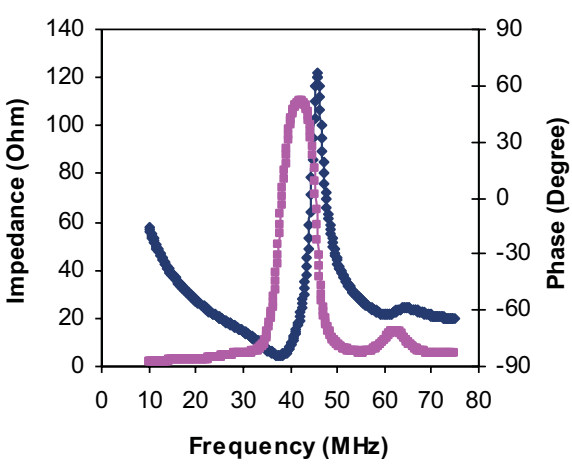

(b)

Figure 7. Resonant mode of the fabricated PMN-PT single crystal micro-array. (a) Impedance and phase vs. frequency of a $60 \mu \mathrm{m}$ thick micro-array. (b) Impedance and phase vs. frequency of a 31 $\mu \mathrm{m}$ thick micro-array.

\section{CONCLUSIONS}

The developed deep etching process for PMN-PT single crystal shows no-noticeable etching induced damage to the crystal, the $\mathrm{d}_{33}$ of single crystal after etching retained its value before etching $(1800-2200 \mathrm{pC} / \mathrm{N})$. An almost vertical etching, $>87^{\circ}$ was achieved with a depth $>60 \mu \mathrm{m}$. The PMN-PT microarray was successfully used for to prototype 1-3 piezoelectric composites. Composites with resonant frequency ranging from $20 \mathrm{MHz}$ to $>45 \mathrm{MHz}$ showed electromechanical coupling coefficients of $\sim 0.72$, which is promising for various piezoelectric sensors and transducers applications.

\section{REFERENCES}

[1] S. Trolier-McKinstry and P. Muralt, "Thin Film Piezoelectrics for MEMS," J. Electroceram. 12 (1-2) 7-17 (2004).

[2] S.E. Park and T.R. Shrout, "Relaxor based ferroelectric single crystals for electromechanical actuators", Mat. Res. Innovat., 1, pp.20-25, 1997.

[3] T. Ritter, X.Geng, K. Shung, P.D. Lopath, S.E. Park, and T.R. Shrout, "Single Crystal PZN/PT-Polymer Composites for Ultrasound Transducer Applications", IEEE Transactions on Ultrasonics, Ferroelectrics, and Frequency Control, Vol.47, No.4, July 2000, pp. 792-800.

[4] M. Zipparo, C. Oakley, W. Hackenberger and L. Hackenberger, "Single Crystal Composites, Transducers, and Arrays", IEEE Ultrasonic Symposium 1999, pp.965-968.

[5] W. Hackenberger, X. Jiang, P. Rehrig, X. Geng, A. Winder, and F. Forsberg, "Broad Band Crystal Transducer for Contrast Agent Harmonic Imaging", 2003 IEEE Ultrasonic Symposium, pp.778-781.

[6] K.C.Cheng, H.L.W. Chan, C.L.Choy, Q.Yin, H. Luo, and Z. Yin, "Single Crystal PMN-0.33PT/Epoxy 1-3 Composites for Ultrasonic Transducer Applications", IEEE Trans. Ultrasonics, Ferroelectrics, and Frequency Control, Vol.50, No.9, Spet. 2003, pp.1177-1183.

[7] S. Wang, X. Li, K. Wakabayashi, and M. Esashi, Deep reactive ion etching of lead zirconate titanate using sulfur
[8] C.W. Chung, Y.H. Byun and H.I. Kim, Inductively coupled plasma etching of $\mathrm{Pb}\left(\mathrm{Zr}_{\mathrm{x}} \mathrm{Ti}_{1-\mathrm{x}}\right) \mathrm{O}_{3}$ thin films in $\mathrm{Cl}_{2} / \mathrm{C}_{2} \mathrm{~F}_{6}$ and $\mathrm{HBr}$ plasma, Proc. 200 ${ }^{\text {th }}$ Electrochemical Society Meeting, 2000.

hexafluoride gas, J. Am. Ceram. Soc., 82(5) pp. 1339-1341, 1999.

[9] J.K. Jung and W.J. Lee, Dry etching characteristics of $\mathrm{Pb}(\mathrm{Zr}$, Ti) $\mathrm{O}_{3}$ films in $\mathrm{CF}_{4}$ and $\mathrm{Cl}_{2} / \mathrm{CF}_{4}$ inductively coupled plasmas, Jpn. J. Appl. Phys. Vol. 40(2001)pp. 1408-1419, 2001.

[10] M. Bale and R.E. Palmer, Deep plasma etching of piezoelectric PZT with $\mathrm{SF}_{6}$, J. Vac. Sci. Technol. B 19(6), pp. 2020-2025, 2001.

[11] P.W. Rehrig, X. Jiang, W. Hackenberger, J.R. Yuan and R. Romley, "Micromachined Imaging Transducer", US Patent Application No. \#11/202,674, 2005.

[12] IEEE Standard on Piezoelectricity, Std. 176-1987, IEEE, New York, 1987.

[13] J.F. Gelly, and F. Lanteri, "Comparison of Piezoelectric (thickness mode) and MEMS Transducers", 2003 IEEE Ultrasonic Symposium, pp.1965-1974.

[14] D. L. DeVoe, and A. P. Pisano, "Modeling and Optimal Design of Piezoelectric Cantilever Microactuators", J. Microelectromechanical Systems, Vol. 6, No.3, September 1997, pp.266-270.

[15] N. Ledermann, P. Muralt, J. Baborowski, M. Forster, and J.P Pellaux, "Piezoelectric $\mathrm{Pb}\left(\mathrm{Zr}_{\mathrm{x}}, \mathrm{Ti}_{1-\mathrm{x}}\right) \mathrm{O}_{3}$ Thin Film Cantilever and Bridge Acoustic Sensors for Miniaturizaed Photoacoustic Gas Detectors", J. Micromech Microeng 14(2004) pp.1650-1658.

[16] J.R.Yuan, X.Jiang, P.W. Rehrig, et al., IEEE Ultrasonic Symposium, 2006. 